\title{
Correction to: Discordance between diet analysis and dietary macronutrient content in four nominally herbivorous fishes from the Southwestern Atlantic
}

\author{
Thiago C. Mendes ${ }^{1,2} \cdot$ Carlos Eduardo L. Ferreira ${ }^{2} \cdot$ Kendall D. Clements $^{3}$
}

Published online: 27 November 2018

(c) Springer-Verlag GmbH Germany, part of Springer Nature 2018

\section{Correction to: Marine Biology (2018) 165:180 \\ https://doi.org/10.1007/s00227-018-3438-4}

The authors would like to correct the error in the publication of the original article. The corrected details are given below for your reading.

In discussion section, fourth sentence of the first paragraph should read as:

"Despite the apparent similarity in the diets of A. chirurgus and S. axillare, they had very distinct nutritional dietary profiles with the latter containing roughly four times the nitrogen and double the carbon content of the former."

The original article can be found online at https://doi.org/10.1007/ s00227-018-3438-4.

Thiago C. Mendes

tcmendes@gmail.com

1 Departamento de Ecologia, Universidade Federal do Rio de Janeiro, Rio De Janeiro, RJ 21941-902, Brazil

2 Reef Systems Ecology and Conservation Lab, Departamento de Biologia Marinha, Universidade Federal Fluminense, Niterói, RJ 24001-970, Brazil

3 School of Biological Sciences, University of Auckland, Private Bag 92019, Auckland 1142, New Zealand 